\title{
Ethical orthopaedics for EFORT, 2014
}

\author{
Michael Benson • Niki Boehler • Miklos Szendroi • \\ Luigi Zagra • Jean Puget
}

Published online: 8 March 2014

(C) EFORT 2014

\section{Ethical orthopaedics for EFORT}

A group of surgeons from around Europe was asked by the EFORT Board to consider how orthopaedic surgeons should make ethical considerations central to their everyday practice. This ethics committee group was initially chaired by Prof. Jean Puget (France) and included Michael Benson (UK), Niki Boehler (Austria), Miklos Szendroi (Hungary) and Luigi Zagra (Italy). Sadly, Prof. Puget died unexpectedly, and the work was completed in his memory.

It is hoped that the recommendations will stimulate discussion and elaboration as we all strive to treat our patients, colleagues and trainees with consideration, skill and care.

\section{Michael KD Benson (Chair of Ethics Committee)}

\section{Jean Puget (deceased)}

It is with the greatest sadness that the authors recall that the contributions made to this ethical study by our first chairman, Prof. Jean Puget, were abruptly halted by his untimely death. We honour his enthusiasm, good humour and deeply held ethical beliefs. The world of orthopaedics is made poorer by his departure.

\author{
M. Benson $(\bowtie)$ \\ Nuffield Orthopaedic Centre, St. Lukes' Hospital, Oxford, UK \\ e-mail: michael.benson@doctors.org.uk \\ N. Boehler \\ Vienna, Austria \\ M. Szendroi \\ Budapest, Hungary \\ L. Zagra \\ Milan, Italy \\ J. Puget \\ Toulouse, France
}

\begin{abstract}
Aims
Specialist societies around the world are formulating the best practice criteria for patient care. European Federation of National Associations of Orthopaedics and Traumatology (EFORT) aims to provide guidance for European orthopaedic surgeons in managing our patients with fairness, honesty and integrity and with a clear understanding of the ethical and moral principles which should underpin this care.
\end{abstract}

\section{Definition}

In its simplest terms, Ethics is the science of human duty. Medical ethics applies moral principles to the values and judgement inherent to the practice of medicine. It includes the essential concepts of professionalism and our relationships with patients, colleagues, trainees and industry. There is clearly a link between the law and ethics, but the former tends to concentrate on rights and the latter on values.

\section{History}

There is nothing new in medical ethics; concerns for our patients' welfare and the proper behaviour of those who treat them date back 4,000 years to the Code of Hammurabi. It is twenty-five centuries since Hippocrates exhorted us "to abstain from doing harm", later interpreted as "First do no harm". There are archives of the literature on medical ethics in general, but remarkably little on surgical and even less on orthopaedic ethics. Standard surgical textbooks make no mention of them.

In the Medieval World, moral principles were developed by Jewish, Catholic and Islamic seers. Thomas Percival first used the phrase "medical ethics" in his "medical jurisprudence" in 
the eighteenth century; his writings were more protective of the physician than the patient but were incorporated into the American Academy of Physicians' first Code of Ethics adopted in Philadelphia [1].

The early twentieth century saw the evolution from a paternalistic doctor/patient relationship towards greater patient autonomy. The Nuremberg Code of 1947, which followed upon non-consensual Nazi research, underlined the rights of a patient to understand what was on offer, the right to choose treatment and the right not to be harmed.

In 2005, a JBJS editorial noted: "Medicine, law and religion are the three traditional learned professions. With professionalism, both privilege and responsibility should come. As surgeons we study to achieve specialised knowledge and supplement this with training and experience. Our patients and our Governments grant us certain privileges but expect us to be guided by ethical principles. We set the standards for entry, assessment, training and certification into our specialty and seek to ensure these standards are maintained throughout a professional lifetime. Our patients allow us the right, after careful explanation, to perform operations upon them which cannot be free of potential complications" [2].

Many publications consider the changing environment in which we practise. The British Medical Association's Medical ethics today: the BMA's handbook of ethics and law runs to 997 pages and is regularly updated [3]. The Journal of Medical Ethics has a wide circulation, and students around the world now study ethical complexity at university.

The excellent AAOS 'Code of ethics and professionalism for orthopaedic surgeons' (revised in 2011) highlights the concerns we should all have for patient welfare and honourable behaviour by treating orthopaedic surgeons [4].

\section{Key considerations in ethical orthopaedic practice}

Background The primary aim of all doctors should be to care for patients to the best of their ability. We must recognise that each patient is unique with widely varying medical, psychological, social and mental characteristics which affect understanding and decision-making [5]. Cesana [6] reminds us of the 'mystery' within each doctor and patient relationship; if we neglect our ethical responsibilities, we overlook the complexity of our patients' needs.

Personal All practising orthopaedic surgeons should combine honesty and integrity with altruism. We need to maintain our own physical and mental health to practise efficiently and strive to balance work, family and recreational pursuits appropriately [7].

Professional We must recognise and work within the limits of our competence. We should consult and listen to other colleagues' advice when we are in doubt. Furthermore, we should respect the patient's right to a second opinion [8]. We must keep up to date by attending relevant meetings and congresses, liaising with colleagues and reading current research and review literature. It is essential to keep accurate, complete and legible records contemporaneously. We should also maintain records of practice, course attendance, etc., and be involved fully in competence assessments. We should regularly review our own practice by audit and take part in relevant local and national databases $[9,10]$.

We should be certain that drugs and treatment are prescribed only when the patient's health has been properly assessed and then offer effective treatment based on the best available evidence. When a cure is not possible, we must do all we can to alleviate pain and distress. In all our dealings with patients, we should be as impartial as possible. We should not be influenced by status, religious or ethnic considerations.

When we have doubts about the facilities available or the competence of a colleague, we should be prepared, if simple discussion fails to resolve the problem, to pursue the matter until the issue is settled.

A recent UK report highlighted the problems which may arise when hospital managers strive to achieve cost savings at the expense of patient care and noted: "The medical profession's technical and scientific brilliance has not been matched by its leadership or compassion" [11]. It is well to remember Martin Luther King's observation: "Our lives begin to end the day we become silent about things that matter."

\section{Orthopaedic surgical relationships with patients and colleagues: honesty and transparency}

We are doctors before we are surgeons, and our first priority must always be to look after our patients to the best of our ability. Our patients deserve our compassion and understanding [12]; they need to choose between any treatments we offer, and it is our professional responsibility to explain options honestly and transparently, simply and clearly. The advice we offer should be based both on the best available evidence and our own experience. The options offered should consider also any limitations imposed by the resources available to us. Whenever possible, as part of our risk/benefit analysis, a simple procedure should be preferred to a complex one [13].

When things go wrong, we must deal with problems with compassion and understanding [14]. Our patients must not feel abandoned, and we should redouble our efforts to support them whether or not the complication can be resolved $[15,16]$.

Our patients and their relatives should understand our commitment to maintaining confidentiality $[17,18]$. Our conduct must justify our patients' trust both in us and in our 
profession; it is essential that we are honest about our own experience and qualifications. Every surgeon should recognise the limitations of his experience, skill and surgical expertise and be prepared to refer to a more experienced colleague when necessary. We must not promise excellent clinical results when the outcome is often unpredictable.

Ethical considerations may sometimes be particularly challenging as, for example, in high-level athletes and those with profound disability who are unable to comprehend the problem or the potential solution [19].

As new techniques and procedures develop, it becomes impossible to have great experience of them all. Close liaison with colleagues should ensure that complex problems are dealt with whenever possible by the most experienced team. Patients appreciate our honesty in these matters. Referrals to colleagues should be made in the patient's best interests and not to gain money, career or scientific advantage.

It is the duty of a more experienced doctor to support junior colleagues as a priority, and not leave them unsupervised or unsupported in managing cases with which they have little experience. Our patients should understand that surgeons work in teams; we must understand that team unity is critical if we are to achieve the best results [20-22].

Professionalism dictates that we must try to understand the complex personal, social and psychological factors associated with illness which may influence our patients' choices. The days of the paternalistic doctor have passed [23]; decisionmaking must lie clearly in the hands of our patients. Our responsibility is to ensure that we have explained fully the benefits and risks associated with any treatment. Time for reflection and other opinions may be needed for the patient to reach a considered decision [8].

We must not discriminate unfairly against patients on the grounds of their likability, politics, status, religion, etc., or allow personal views or possible financial gain to affect the impartiality of the advice we offer.

If things go wrong, we must be open and honest with patients and try to put matters right if possible. We should explain fully and promptly what has happened, the likely effects and how we intend to remedy any problems [24]. If a patient complains about our care, we must respond promptly, fully and honestly and be prepared to apologise when appropriate. The complaint should not adversely affect the care and treatment we continue to offer.

We must avoid unjustified criticism of a colleague in front of other colleagues, trainees or patients (it is improper for the patient and colleagues and reflects badly on us). We should support colleagues when appropriate if they are the subject of unjust claims or blame. As litigation becomes increasingly common, it is essential that medical experts give unbiased and clearly considered advice which must reflect the standards of the whole profession and not simply those of the superspecialist.
However, if concern is brought to our attention about a colleague's performance, we are obliged to act. This may involve inappropriate patient management, inadequate standards of surgery or follow-up, health matters, unethical conduct and financial irregularity. When the concern is minor, it is wise to discuss matters with the surgeon before proceeding further. If, however, there is any worry about patient safety, the concern must be promptly escalated to involve the medical director and hospital management.

\section{Informed consent}

Informed consent is now a mandatory part of everyday clinical practice especially when an operation is involved [25]. Such consent has medico-legal implications, but even more importantly, it demands our ethical concern [26]. It is not enough to make it a bureaucratic procedure where an operation is listed and a signature requested [27]. The procedure must be carefully and fully explained in understandable terms to the patient or responsible person $[28,29]$. The informed consent form is not a substitute for properly educating a patient; it simply reflects that an appropriate discussion has taken place [30, 31]. Risks, alternatives, advantages and disadvantages of the proposed treatment must be discussed [32, 33]. The risks should not be minimised nor the benefits exaggerated. Both success and failure and the actions necessary should problems develop should be considered [34]. The consent form should be witnessed by a surgeon fully conversant with the procedure [35]. The patient should be given time to ask questions. With adequate time for information and questions, our patients are better able to make their own decisions and participate fully in their treatment even if problems arise. An understanding alliance between patient and doctor fosters improved health-care outcomes and minimises the risk of developing an antagonistic or litigious relationship [30]. Potential conflicts of interest, such as research, industry grants, financial or other rewards for the doctor or institution, should be discussed. Once again, honesty and transparency play key roles in discussing carefully our treatment plans with our patients. Lemaire [26] reminded us that our patients often fail to understand the issues and, furthermore, forget most of the information provided. They remember better how the information was given rather than its content which, in turn, should remind us of the importance of establishing rapport whenever possible.

\section{Doctors' fees or honoraria}

Fees, when payable for private practice, should reflect the time, complexity, skill and experience of the surgeon. Patients should be made aware that they will not be abandoned 
if they run out of money as a result of unforeseen circumstance or complication.

The decision to treat should not be based on economic reasons alone. The patient in both privately and publicly funded systems should base treatment decisions on the need and not on finance. In the public system, doctors must not seek money, gifts or any other personal advantage [36]. The obsolete term 'honorarium' has its origins in the idea that a patient may give an honorary prize for the doctor's medical knowledge and art. Gifts should not be solicited as such inducements might tempt the opportunistic but unethical surgeon to expedite treatment, assure the patient of his personal involvement or improve accommodation in hospital.

Furthermore, with today's limited resources and irrespective of whether treatment is public or private, we should not advise expensive treatments or devices with no proven improved patient outcomes [37]. As ever, honesty and transparency should be our guiding principles.

\section{The orthopaedic surgeon's responsibility for teaching and training}

As teachers and trainers in orthopaedics, we carry a burden of responsibility to ensure that future surgeons develop both requisite knowledge and the ethical standards needed to look after patients with skill and care. Each of us must be aware that our students, trainees, colleagues and patients learn in part by the examples we set. We must share medical knowledge and teach appropriate surgical techniques. We must also ensure our trainees understand the importance of compassion, understanding and appropriate explanation for all our patients $[38,39]$. Critically, we must stress that our patients' interests always come first, and it is they who must understand the risk/benefit balance for any procedure and decide whether to proceed.

It may be difficult to separate personal interest from our treatment options. Many of us have industry and research links which tempt us to skew the advice we give. It is a temptation that we should resist [40]. If there is any potential conflict of interest, this must be explained carefully to the patient, and a time for reflection and family discussion should be allowed before a decision is made [32]. A failure in communication is the most common cause for patients to complain [24]. In our teaching and training, it is vital that we pass on these ethical principles.

Surgeons do not work in isolation; it is essential that we work in teams. Good team working is critical in building the best conditions for practice $[20,22]$. The teams vary in size and constitution, but plans of action, especially when they involve a substantial change, are best developed after careful debate [21]. Our students and trainees gain insight by participating in such debates. We should remember that, even if criticism is justified, it is unacceptable to humiliate any colleague or trainee in front of a patient, nurse or other doctor.

Our goal in teaching and training is to develop informed, technically competent surgeons in the future who are fully aware of the need to treat patients with honesty, skill and consideration.

\section{The ethics of orthopaedic research}

Research is essential if we are to make progress. In general, it should increase and develop our understanding of disease and its management with the aim of improving patient outcomes. Research must be considered by the institution's ethical committee. Where possible, laboratory experiments should be preferred to animal or human ones.

Anyone who conducts patient-related research should understand the requisite ethical, institutional and government guidelines which guide behaviour. While these vary in Europe, some core principles are common to all. Patients must be fully informed about the objectives, risks and potential benefits of the study and given time to reflect before agreeing [31]. While the details of the research project may be given by a junior team member, a senior investigator should outline the study to the patient and be sure that it is properly understood. Patient volunteers should be made aware of the outcomes of the research in which they participate [32].

There are many potential ethical pitfalls in research [41]. To counteract, these honesty and integrity are essential. Sponsorship is necessary for research, and this may come from our institutions, charities, governments or industry. If the investigator and his team stand to benefit individually or institutionally either financially or in kind, the patient should be made fully aware [40]. All those who are involved in the project must understand the financial and ethical considerations of such sponsorship.

Poor results should not be excluded on any pretence; the outcomes of the study should be presented in a timely, objective, accurate and complete way [42]. Plagiary should be avoided, and proper acknowledgement should be paid to sources. No individuals' names should be added to a research paper unless they have contributed significantly. The results of the research should be shared with all those who volunteered for the project.

Complete records of all scientific researches should be retained for at least 5 years after publication to ensure that a critical review could be undertaken should the need arise.

Where a surgeon has collaborated in developing a new instrument or technique, it is reasonable for him/her to be financially rewarded. When a surgeon is involved in clinical trials of a new prosthesis which is not of his/her design and the surgeon's name is used to facilitate sales, personal rewards are less satisfactory; it is better if the institution or department 
receives such benefits. No surgeon should be persuaded to use an appliance against his/her better judgement. Once again, patients must be fully informed of any payment from a third party which may influence their management.

It sometimes happens that an investigator finds that, on further review, the excellent initial results cannot be reproduced. It is essential that these later results are reported to prevent unnecessary widespread damaging usage. Close liaison with the manufacturer is fundamental in such matters.

\section{Intellectual property}

The concept of intellectual property is straightforward; most research institutions are well aware of the rules which govern it and the patents which may be needed. Nonetheless, the principles underlying the development and appropriate contracts need to be clearly established before a commercial support is negotiated.

There have been many examples of ethical misconduct in scientific research [40,41]. We all have responsibility to report such lapses. The US Public Health Service (PHS) and the National Science Foundation (NSF) include, under the umbrella of 'scientific misconduct,' plagiarism, deception, falsification and/or fabrication of data together with "other practices that seriously deviate from those that are commonly accepted within the scientific community for proposing, conducting or reporting research." We must, however, try to distinguish between honest error and deliberate falsification and recognise that there may be differences in the analysis and interpretation of data [7].

It is widely but not universally recognised that disclosures of potential benefits and rewards should be presented before every scientific paper and presentation. We should persuade governments, professional organisations and medical journals that conflicts of interest should always be declared in every medium [43]. EFORT believes that disclosures should be fully and transparently declared, and these include grants, royalties, stock options, research funds, travel and accommodation costs and any financial interest for the surgeon, relatives, institutions, departments or colleagues. The surgeon who reports on experience with a product or procedure must disclose any economic advantage received.

\section{Research and publication}

There should be an end to the haphazard way in which new surgical techniques and products are introduced [44, 45]. Patients may be attracted by the latest trend before it has been properly tried and evaluated. The history of orthopaedics is littered with widely different procedures which have been proven of little value. In promulgating a new technique, surgeons often compare poorly with the pharmaceutical industry and its rigorous controls [46].

All orthopaedic surgeons had recognised that ethical committee approval must be sought before prospective studies or additional investigations are undertaken. We should encourage ethical committees to review progress in these studies to ensure that they remain focused, safe and relevant. Although we know that research must be honest, unbiased and rigorous, fraudulent publication remains to be a risk as surgeons are tempted to present their own results favourably. Editors and those who review for medical journals must be aware of possible fraud and be prepared to question scientific papers if there is doubt [47].

\section{Relationships between orthopaedic surgeons and industry}

It is inevitable that conflicts of interest may arise when the ambition of the individual is in conflict with ethical obligation. Such conflicts may arise when our financial, medical and political goals interfere with our ties to the pharmaceutical and manufacturing industries [40]. These industries are now very aware of the pitfalls which may accompany inappropriate links with surgeons, and for example, the Eucomed Code of Ethical Business Practice [48] very clearly defines how the necessary close links should be forged.

Conscience is a tender plant and must be nurtured by us all. We should know when our actions are not solely in the best interests of our patients. Our dealings must always be seen to be 'reasonable'. If we maintain our own ethical principles, we will pass on to the next generation of surgeons' ideals every bit as important as their surgical skills.

In an increasingly critical world, we cannot simply assume that all surgeons are above reproach and revered by their patients. As an example, if we accept gifts from the pharmaceutical and manufacturing industries, it may have implications for the relationship with our patients. It risks undermining their confidence in our ability to offer impartial advice [49]. EFORT should set standards which reassure our patients and politicians that we uphold those ethical principles which should protect the trusting relationship between patient and doctor. As surgeons, our dealings with the industries which provide our medicines and devices must be clear-cut, open and defined.

Our relationships with industry should be open, honest and transparent. Each depends heavily on the other, and close liaison is essential. These links should obey certain principles, orthopaedic surgeons should preserve their independence, and no agreements with industry should be accepted if they include conditions which might interfere with the surgeon's surgical and prescribing practices. They must comply with national and local laws. The ethical administrative principles, including all relevant contracts, should be confirmed in 
writing by the hospital administration which must be satisfied that they are fair and equable. Where patient care is involved, the patient should be made fully aware of the surgeon's industry links and of any benefits that might accrue.

All agreements, reports and invoices should be fully documented, and a copy should be retained by each participant. These must describe the collaboration details, the services to be performed and the method of reimbursement.

Industry-sponsored product promotional meetings, training and education

It is appropriate for industry to sponsor these. When covering the costs of attending them, it is better for industry to reimburse the orthopaedic department than the individual surgeon or trainee in the interests of openness. If industry is promoting an event, it may be responsible for the travelling and accommodation costs of those attending. Expenses should include reasonable travel, food and accommodation costs. It is reasonable for orthopaedic instructors at such meetings to be paid a fee. Any recompense should be declared. No uninvolved accompanying person should be eligible for any expenses.

The interaction between manufacturers and orthopaedic surgeons may differ between countries. Financial recompense for meeting attendance is more critical in countries where surgeons are less well-rewarded for their activities. It is important to remember that junior trainees are often in greater need of support than their seniors.

Industry support for orthopaedic and allied educational conferences

Support for orthopaedic surgeons to attend local, national and international conferences is fine, provided that it complies with hospital, local and national guidelines. The support may include financial, scientific, technical and organisational assistance. It is essential that support is reasonable, and it should cover standard rather than luxury fares, fees and accommodation. Such support should be open and declared.

Industry financial support for conference organisers should follow a well-planned programme to which local, national and, where indicated, international committees have agreed. Satellite symposia at appropriate conferences may be similarly reimbursable.

While industry may contribute to the scientific content and faculty constitution, it should be in liaison with orthopaedic surgeons if the symposium is to be recognised as having an educational value. In all cases, there should be a written contract, agreed by both parties and the appropriate hospital or university authority, and this contract must be disclosed.
Orthopaedic consultant advice to industry

This may take many forms; it includes research participation on advisory boards, presentations at company-sponsored training, third party conferences and product collaboration. The collaboration should be transparent. A written agreement signed by both parties and the appropriate hospital or university body should set out the relevant issues. While financial recompense may be an important part of the collaboration, a surgeon should not be paid simply because he/she uses a particular implant. Consultant advisors should be selected on the basis of their expertise and not on the basis of the volume or value of their practice. Any collaboration should be open and transparent. It is the surgeon who should be sure, for example, that in any patient review, none should be omitted simply because their results do not correspond to the norm. Remuneration should reflect the surgeon's contribution and not the value of the product.

\section{Advertising}

While many surgeons are disconcerted by advertisements promoting the skills of one particular surgeon, institute or technique, there are surprisingly few official restrictions in place.

In 2002, the Professional Conduct, Etiquette and Ethics Committee of the Indian Medical Council advised that the "soliciting of patients directly or indirectly by a physician, by a group of physicians or by institutions or organisations is unethical". A physician should "not invite attention to himself or to his professional position, skill, qualification, achievements, attainments, specialities, appointments, associations, affiliations or honours and/or of such character as would ordinarily result in his self aggrandizement".

Gillon in his 1989 editorial highlighted the problem: while there is a long-standing disapproval of self-promotion, patients have the right to choose both their surgeon and their treatment and unless they have access to accurate information they are unable to make an informed decision.

The American Medical Association's ethical code on advertising and publicity notes simply that we should not deceive the public: a doctor "may publicize him or herself... through any commercial publicity or other form of public communication (including any newspaper, magazine, telephone directory, radio, television, direct mail, or other advertising) provided that the communication shall not be misleading because of the omission of necessary material information, shall not contain any false or misleading statement, or shall not otherwise operate to deceive" [50].

In the UK, the General Medical Council's advice on good medical practice is clear: in providing and publishing information about our services, we must be sure that the 
information is factual and verifiable; we must not make unjustifiable claims about the quality or outcomes of our services in any information we provide to patients; we must not offer guarantees of cures, nor exploit patients' vulnerability or lack of medical knowledge [51]. We must not put pressure on people to use a service, for example, by arousing ill-founded fears for their future health [52].

Advertising is now inevitable; surgeons and institutions need to publicise their skills and expertise in the public interest but should be always responsible and honest and refrain from claiming precedence over other individuals and organisations.

\section{Social media and medical ethics}

Surgeons now have many opportunities to interact with colleagues, industry and their patients not only by newspaper, radio and television but also through social media [17, 53, 54]. We should address these present challenges. We must maintain our patients' confidentiality $[17,18]$, follow ethical guidelines, report unprofessional and/or dishonest advertising and be aware that publicity may both benefit and harm career prospects; information should be kept up to date, and we should remember that social sites allow both positive and negative commentaries [55].

Once again, honesty, integrity and a clear aspiration to improve our patients' health should be the driving force behind any information we publish.

\section{Summary}

As orthopaedic surgeons, we should continue to treat our patients with honesty, compassion, skill and care. Our aims should always be to 'cure and to care' [56]. If we rely solely on technique and neglect our ethics of service, we become a trade and not a profession [51]. The therapeutic alliance between doctor and patient should be based on understanding, confidence and cooperation and forms the platform for a successful treatment [57].

We have a long tradition of earning the respect of our patients and colleagues, and we must ensure that we continue to deserve the trust they place in us.

\section{References}

1. American Academy of Physicians (1847) Code of ethics. American Medical Association, Chicago

2. Benson MK, Bourne R, Hanley E Jr, Harrison J, Jodoin A, Nicol R, van Wyk L, Weinstein S (2005) Ethics in orthopaedic surgery. J Bone Joint Surg (Br) 87(11):1449-1451
3. British Medical Association (2013) Medical ethics today: the BMA's handbook of ethics and law.

4. American Academy of Orthopedic Surgeons \& the American Association of Orthopedic Surgeons: Code of ethics and professionalism for orthopedic surgeons (Adopted October 1988. Revised: 1991, 1995, 2001, 2002, 2004, 2005, 2009, 2011)

5. Gadamer HG (1994) In: Grieco S, Lingiardi V (eds) Dove si nasconde la salute. Cortina, Milano

6. Cesana G (2005) Il "Ministero" della salute. Note introduttive alla medicina. Fiorentina, Firenze

7. Ariyan S (1994) Of mice and men. Honesty and integrity in medicine. Ann Surg 220(6):745-750

8. McCarthy EG, Finkel ML (1981) Second consultant opinion for elective orthopedic surgery. Am J Public Health 71(11):1233-1236

9. Capelli O, Riccomi S, Scarpa M, Magrini N, Rovatti E, Cacciapuoti I, Brambilla A (2012) Clinical audit in primary care: from evidence to practice. In: Capelli O (ed) Primary care at a glance - hot topics and new insights. ISBN: 978-953-51-0539-8

10. National Institute for Clinical Excellence (2002) Principles for best practice in clinical audit. Qual Saf Health Care 11:392, Radcliffe Medical, Abingdon

11. Halligan A (2013) The Francis report: what you permit, you promote. J R Soc Med 106(4):116-117

12. Cassell EJ (1995) The healer's art. The MIT, Cambridge

13. Aebi M, Gunzburg R, Nazarian S, Olmarker K (1997) Technical advances, financial problems and ethics. Eur Spine J 6(4):221

14. Balint M (1970) Medico, paziente e malattia. Feltrinelli Ed, Milano

15. Hauerwas S (1986) Suffering presence: theological reflections on medicine, the mentally handicapped and the Church. T\&T Clark, Edinburgh

16. Pellegrino ED, Thomasma DC (1993) The Christian virtues in medical practice. Oxford University Press, Oxford

17. Estroff SE, Walker RL (2012) Confidentiality: concealing "things shameful to be spoken about". Virtual Mentor 14(9):733-737

18. Ferguson AH (2012) The evolution of confidentiality in the United Kingdom and the West. Virtual Mentor 14(9):738-742

19. Murthy AM, Dwyer J, Bosco JA (2012) Ethics in sports medicine. Bull NYU Hosp Jt Dis 70(1):56-59

20. Moe RH, Haavardsholm EA, Grotle M, Steen E, Kjeken I, Hagen KB, Uhlig T (2011) Development of a brief multidisciplinary education programme for patients with osteoarthritis. BMC Musculoskelet Disord 12:257

21. Newhouse RP, Spring B (2010) Interdisciplinary evidence-based practice: moving from silos to synergy. Nurs Outlook 58(6):309-317

22. Westli HK, Johnsen BH, Eid J, Rasten I, Brattebø G (2010) Teamwork skills, shared mental models, and performance in simulated trauma teams: an independent group design. Scand J Trauma Resusc Emerg Med 18:47

23. Balint J, Shelton W (1996) Regaining the initiative. Forging a new model of the patient-physician relationship. J Am Med Assoc 275(11):887-891

24. Vincent C, Young M, Phillips A (1994) Why do people sue doctors? A study of patients and relatives taking legal action. Lancet 343(8913):1609-1613

25. Jones KB (2007) Surgeons' silence: a history of informed consent in orthopaedics. Iowa Orthop J 27:115-120

26. Lemaire R (2006) Informed consent - a contemporary myth? J Bone Joint Surg (Br) 88(1):2-7

27. Amarasekera SS, Lander RO (2008) Understanding of informed consent and surgeon liability by the public and patients. J Orthop Surg (Hong Kong) 16(2):141-145

28. Ibrahim T, Ong SM, Taylor GJ (2004) The new consent form: is it any better? Ann R Coll Surg Engl 86(3):206-209

29. Sahin N, Oztürk A, Ozkan Y, Demirhan Erdemir A (2010) What do patients recall from informed consent given before orthopedic surgery? Acta Orthop Traumatol Turc 44(6):469-475 
30. Brenner LH, Brenner AT, Horowitz D (2009) Beyond informed consent: educating the patient. Clin Orthop Relat Res 467(2):348-351

31. Langdon IJ, Hardin R, Learmonth ID (2002) Informed consent for total hip arthroplasty: does a written information sheet improve recall by patients? Ann R Coll Surg Engl 84(6):404-408

32. Bal BS, Choma TJ (2012) What to disclose? Revisiting informed consent. Clin Orthop Relat Res 470(5):1346-1356

33. Barritt AW, Clark L, Teoh V, Cohen AM, Gibb PA (2010) Assessing the adequacy of procedure-specific consent forms in orthopaedic surgery against current methods of operative consent. Ann R Coll Surg Engl 92(3):246-249

34. Beresford-Cleary NJ, Halliday J, Breusch SJ, Biant LC (2012) Consent process for elective total hip and knee arthroplasty. J Orthop Surg (Hong Kong) 20(1):140

35. Singh S, Mayahi R (2004) Consent in orthopaedic surgery. Ann R Coll Surg Engl 86(5):339-341

36. Gaufberg E (2007) Should physicians accept gifts from patients? Am Fam Physician 76(3):437-438

37. Lie RK (2004) Research ethics and evidence based medicine. J Med Ethics 30(2):122-125

38. Rabow MW, Evans CN, Remen RN (2013) Professional formation and deformation: repression of personal values and qualities in medical education. Fam Med 45(1):13-18

39. Saito Y, Kudo Y, Shibuya A, Satoh T, Higashihara M, Aizawa Y (2011) Building medical ethics education to improve Japanese medical students' attitudes toward respecting patients' rights. Tohoku J Exp Med 224(4):307-315

40. Carr AJ (2005) Which research is to be believed? The ethics of industrial funding of orthopaedic research. J Bone Joint Surg (Br) 87(11):1452-1453

41. Bailey CS, Fehlings MG, Rampersaud YR, Hall H, Wai EK, Fisher CG (2011) Industry and evidence-based medicine: believable or conflicted? A systematic review of the surgical literature. Can J Surg 54(5):321-326

42. Kubiak EN, Park SS, Egol K, Zuckerman JD, Koval KJ (2006) Increasingly conflicted: an analysis of conflicts of interest reported at the annual meetings of the Orthopaedic Trauma Association. Bull Hosp Jt Dis 63(3-4):83-87
43. Okike K, Kocher MS, Wei EX, Mehlman CT, Bhandari M (2009) Accuracy of conflict-of-interest disclosures reported by physicians. N Engl J Med 361(15):1466-1474

44. Berjano P, Biaco E, Bianconi M, Bozzolan M, Iovine R, Jefferson T, Lo Monaco A, Padua R, Romanini E, Testa M, Torre M, Traina F, Tucci G, Zagra L, Zanoli G (2004) Revisione sistematica sulle protesi d'anca: affidabilità dell'impianto. Programma Nazionale per le Linee Guida, Ministero della Salute, Documento 8, Roma

45. Malchau H (1995) On the importance of stepwise introduction of new hip implant technology. Institute of Surgical Science University of Goteborg, Sweden

46. Beauchamp TL, Childress JF (1994) Principles of biomedical ethics, 4th edn. Oxford University Press, Oxford

47. Smith R (2006) The trouble with medical journals. J R Soc Med 99: 115-119

48. Eucomed Medical Technology (2008) Eucomed code of ethical business practice. http://www.eucomed.org/key-themes/ethics

49. Green MJ, Masters R, James B, Simmons B, Lehman E (2012) Do gifts from the pharmaceutical industry affect trust in physicians? Fam Med 44(5):325-331

50. Havard JD (1989) Advertising by doctors and the public interest. BMJ 298(6678):903-904

51. Dyer AR (1985) Ethics, advertising and the definition of a profession. J Med Ethics 11(2):72-78

52. Gillon R (1989) Advertising and medical ethics. J Med Ethics 15(2): $59-60,85$

53. American Academy of Orthopedic Surgeons \& the American Association of Orthopedic Surgeons (2012) Social media in healthcare - a primer for orthopaedic surgeons

54. Gholami-Kordkheili F, Wild V, Strech D (2013) The impact of social media on medical professionalism: a systematic qualitative review of challenges and opportunities. J Med Internet Res 15(8):e184

55. Timimi FK (2012) Medicine, morality and health care social media. BMC Med 10:83

56. Agazzi E (1992) Il bene, il male e la scienza: le dimensioni etiche dell'impresa scientifico-tecnologica. Rusconi Ed, Milano

57. Buzzi E (2013) Etica della cura medica. La Scuola Ed, Milano 